\title{
Prevalence of Cs and Early Maternal Complication, among Cs Delivered Mothers at Jugol Hospital, Harar, Ethiopia
}

\author{
Masresha $\mathrm{L}^{{ }^{*}}$, Niguse $\mathrm{M}^{2}$ and Iffa $\mathrm{MT}^{3}$ \\ ${ }^{1}$ Department of Midwifery, Harar Health Science College, Harar, Ethiopia \\ ${ }^{2}$ Department of Nursing, Harar Health Science College, Harar, Ethiopia \\ ${ }^{3}$ Department of Nursing and Midwifery, Haramaya University, Harar, Ethiopia
}

*Corresponding author: Masresha L, Department of Midwifery, Harar Health Science College, Harar, Ethiopia, Tel: +251-0911947787, E-mail: masreshaleta3@gmail.com

Citation: Masresha L, Niguse M, Iffa MT (2019) Prevalence of Cs and Early Maternal Complication, among Cs Delivered Mothers at Jugol Hospital, Harar, Ethiopia. J Health Sci Stud 1(1): 105. doi: 10.15744/2767-9136.1.105

Received Date: April 23, 2019 Accepted Date: May 22, 2019 Published Date: May 24, 2019

\begin{abstract}
Background: The rise in cesarean delivery has higher maternal risks for the current and subsequent pregnancies. It is associated with short and long term complication as any surgical procedure. As prevalence of Cesarean section increased beyond reminded range without concomitant decrease in maternal and neonatal mortality and morbidity rates significant concern that $\mathrm{C} / \mathrm{S}$ is over used once women has had one birth by Ceserean section.
\end{abstract}

Objectives: The purpose of this study was to assess prevalence of cesarean section and early maternal complication among cesarean section delivery mothers, at Jugol hospital, Harar, Ethiopia.

Method and Material: Institutional based retrospective cross-sectional study design was used at Jugal hospital eastern Ethiopia. The study population comprised 1620 maternal cards who were admitted in the maternity unit following cesarean section delivery from July 2014-June 2017 at Jugal hospital. The sample size of the study was 284 and systematic random sampling method was employed to select the study participants. Data was collected using a pretested checklist and data was analyzed accordingly by using computer software SPSS 20 version.

Result: There were 7284 deliveries at Jugol Hospital, of which 1,620 were by cesarean section, a prevalence of $22.2 \%$. Out of the mothers delivered at hospital by cesarean section, 193(68\%) were multiparas and the rest were primiparas. 91 (32\%) of them had 2-3 Anti natal care follow up, 21(7.3\%) had four (4) time anti natal care follow up and 18(6.3\%) had one anti natal care follow up. From the total 46, $51 \%$ of complication occurred, $20(7 \%)$ were puerperal sepsis and $10(3.52 \%)$ were postpartum hemorrhage. From the association test, there was strong association between post $\mathrm{C} / \mathrm{S}$ complication and duration of labor \& ANC of mothers while $\mathrm{C} / \mathrm{S}$ status \&previous $\mathrm{C} / \mathrm{S}$ scar do not affect the outcome of mothers.

Conclusion and Recommendation: Cesarean section rate (22.2\%) observed in this review was not associated with higher morbidity. Low antenatal care follow up, emergency Ceserean section and prolonged labor was associated with high rate of sepsis\& postpartum hemorrhage.

Keywords: Pattern; Cesarean Section; Deliver; Maternal Complication; Maternity Unit

List of acronyms and abbreviation: ANC: Antenatal Care Visit; BSC: Bachelor of Science; C/S: Cesarean Section; DVT: Deep Vein Thrombosis; EDHS: Ethiopian Demographic and Health Survey; GA: Gestational Age; HHSC: Harar Health Science College; HFSUH: Hiwot Fana Specialized University Hospital; JH: Jugol Hospital; JSUH: Jimma Specialized University Hospital; OPD: Outpatient Department; PPH: Postpartum Hemorrhage; PROM: Premature Rupture of Membrane; SDG: Sustainable Development Goal; SPSS: Statistical Package for Social Science; UTI: Urinary Tract Infections; WHO: World Health Organization

\section{Background}

Cesarean section can be defined as is a surgical procedure in which one or more incision made through mother's abdomen to deliver one or more babies [1]. Currently it is estimated about 20 million CS deliveries occur each year in the world [2]. This makes it the most frequent abdominal surgery performed in adults. The number of women having babies born by cesarean section is rapidly growing in a continuous way in both the developed and developing countries [3] for example, in Latin America especially in Brazil [4]. 
In United States approximately 1.2 million women had a cesarean birth and across worlds likes in United Kingdom, Brazil, and within the country in Ethiopia in Harar was high prevalence rates [5-7]. The Increment associated with this surgical procedure is that rapid decrease in both mortality and morbidity of fetus and mothers who undergone Cesarean sections. For example, in the early 2005 maternal mortality after Cesarean section was estimated to be below 1 per 1000 and this increase in safety encouraged obstetricians to find more and more reasons for carrying out this operation. However, there are still complications associated with this procedure. Maternal morbidity associated with Cesarean section is five to ten times greater than that associated with vaginal Delivery [8].

So, if the rate of Cesarean section which is higher the recommended of WHO it would have negative effect on both maternal and fetus health worldwide. In addition maternal \& neonatal morbidity and mortality in developing countries especially in Sub-Saharan country are very high. In most of sub-Saharan Africa, rates of caesarean sections are low. In West Africa where they account for less than expected births this means that doctors might not be as proficient in medical procedures, resulting in substandard care and sometimes death of the mother. In most of countries in sub Saharan Africa there are surgical services available in referral facilities, but the resources are limited, quality of care is heterogeneous, and distance to the facility is frequently a real barrier for people living in rural regions and maternal morbidity and mortality remain very high [9].

As pattern of Cesarean section increased beyond reminded range without concomitant decrease in maternal and neonatal mortality and morbidity rates significant concern that $\mathrm{C} / \mathrm{S}$ is over used once women has had one birth by Ceserean section, some obstetricians believe all subsequent birth must be performed the same way and increase in procedural complication [10,11]. For nearly 30 years, the international healthcare community has considered the ideal rate for caesarean sections to be between $5 \%$ and $15 \%[5]$.

Therefore, extremely high or low caesarean delivery rate is a significant quality of care issue, and it may also indicate the mismatch between evidence and practice in obstetrics.

Despite low national $\mathrm{C} / \mathrm{S}$ rate, institutional c/s rate is high beyond recommended ranges [12]. To mention a few $\mathrm{C} / \mathrm{s}$ rate at Addis Ababa was 21.8\%, Harar hospitals 34.3\%. Study conducted at Jima specialized hospital in 2014 suggested that C/S rate of $28.1 \%$ which is significantly high rate $[13,14]$. Another study conducted in Jimma specialized university hospital 2016 suggested that C/S rates were $22.2 \%$. Out of mother delivered at hospital by $\mathrm{C} / \mathrm{S}$ were $64.4 \%$ multi Para and the rest were prim papa. Among these 87.7\%, of them 2-4 ANC follow up, 6.4\% had greater than 4 ANC follow up and the rest 5.8\% had no ANC follow up [15].The rises in cesarean delivery are associated with higher maternal surgical risks for the current and subsequent pregnancies. It includes short and long term complication as any surgical procedure. Therefore, it is important for health workers to understand the short and long term complication of both low and high $\mathrm{C} / \mathrm{S}$ rate as well as safe and appropriate opportunities to prevent over use of $\mathrm{C} / \mathrm{S}$. This research was aimed to assess prevalence of $\mathrm{C} / \mathrm{S}$ and early complication rate among $\mathrm{C} / \mathrm{S}$ delivery at Jugol Hospital retrospectively in three years period. In general the impact of $\mathrm{C} / \mathrm{S}$ increases from time to time. So study described the prevalence and complication of $\mathrm{C} / \mathrm{S}$ among all deliveries at Jugol Hospital in stated time period.

Findings of this study leading to new problems for further investigation, signaling and motivating the various stakeholders to take appropriate actions by incorporating the health workers to understand the short and long term complication of $\mathrm{C} / \mathrm{S}$ as well as safe and appropriate opportunities to prevent over use of $\mathrm{C} / \mathrm{S}$ and used to improve quality of care.

Thus, the results of this study were provide information for health workers about prevalence of C/S and early complication rate at Jugol Hospital, which were help the health workers to take action/measure and re plan to improve the situation and other researchers can use it as a baseline evidence for further studies.

\section{Method and Material}

Institutional based cross-sectional record review study design was employed from July 2014-June 2017, using systematically selected maternal cards from Jugal Hospital. The study was conducted at Jugal Hospital which is found in Harar town, located in Eastern Ethiopia, $526 \mathrm{~km}$ East of Addis Ababa.

Jugal Hospital is a regional hospital which was established in 1902 E.C and currently gives health services in six departments' obstetrics and gynecology, pediatrics and child health, Internal Medicine, Surgery and Ophthalmology.

These Hospital was received referral cases from different Health centers about to $100 \mathrm{KM}$ away from the hospital, which are found in the region and the hospital itself referred complicated cases to nearby specialized referral hospital known as Hiwot fana specialized referral hospital.

Obstetrics and gynecology department has 3 wards (gynecology, maternity and Labor) and OPD. At Hospital there were different professions in serving community like Specialist, Surgeon, Internist, Gynecologists, Doctors, Dentist, Ophthalmologist, Pharmacist, Nurses, and Midwifers etc. and in Operation rooms were 1 General surgery, 3 Gynecologist, 2 Emergency surgeries, 8 Anesthesia nurse, and 9 Nurses were providing service. Also hospital total delivery rate as data of hospital reports showed that 5 per day, 33 per week and around 194 per month from this rate of C/S were 3 per day, 11 per week and around 45 per month. 
We use a systematic sampling technique and sample size was determined by using a single proportion sample size calculation formula among 284 maternal cards. Assuming the prevalence of C/S taken from study conducted in Addis Ababa Ethiopia in 2014, which was similar to our study, which was 0.34 and [6], margin of Error 5\% and 95\% confidence interval and since the numbers of the study population $(\mathrm{N}=1620)$ are less than 10,000 we use correction formula so the sample size become 284 . Since the total number of mothers delivered by CS at jugal hospital from July 2014-June 2017 G.C were 1620 and the calculated sample size is 284 , so the ratio(K) of the two become 6 .So data were collected every six cards after randomly selecting the first cards from 1 to 6 until calculated sample size reached. All complete maternal cards who delivered by C/S from July 2014-June 2017 were included in the study and cards which has no incorporating the outcome variable were excluded from the study.

A pre-tested checklist was used for collecting the data. Data were collected from December 10-25/2018 by trained three BSc midwives, from the patient charts and registry books through a systematic sampling method by selecting one card at a time from every six cards, in case the selected card not fulfill the inclusion criteria, next card will be selected and again count another six cards starts from the selected card for the next selection. Before actual data collection, the checklist was pre-tested in 5\% of maternal cards at Hiwot fana specialized university hospital Harari region, which was not selected for the study using randomly selected eligible maternal cards who were admitted from July 2014-June 2017 and modified the checklist based on the problems identified. This helps to ensure the clarity, ordering, consistency and acceptability of the checklist. After this, the checklist was ready after necessary corrections and training was given for data collectors for 3 days at the time of data collection. During data collection, the checklist was checked for completeness on daily basis by the data collector themselves and the supervisors and also rechecked by the principal investigators to maintain the quality of data.

After data collection, each checklist was checked for completeness, then coded and entered into SPSS for Windows version 20 for cleaning, editing, and analysis. The results was presented in the form of tables, figures and text using frequencies and summary statistics such as mean, mode, standard deviation and percentage to describe the study population in relation to relevant variables.

In order to confirm the ethical and legal standard of the investigator, approval was obtained from the ethical review board of Harar Health Science College. The survey was commenced after written consent obtained from Jugal hospital.

\section{Operational Definition}

Complete cards: A card which has a progress \& final clients outcome registered during inpatient treatment.

Incomplete cards: A card which has no incorporating the outcome variable.

Early C/S complication: Presence of any of the following post c/s complication like hemorrhage, infection, Deep vein thrombosis (DVT), maternal death until the time of client discharge.

Emergency C/S: C/s operation done as fast as possible within 30 minute of physician decision to operate.

Elective C/S: cesarean section delivery which is planned either in medical condition or maternal request in the absence of any maternal or fetal indication.

Preterm baby: Those babies delivered before 37 weeks of GA

Term baby: Those babies delivered after 37 weeks of GA

Post term baby: Those babies delivered after 42 weeks of GA

Prolonged Labor: Labor lasts greater than 24 hours

Early post CS complication: Development of complications after a CS within 24 hours of a procedure

\section{Result}

\section{Socio Demographic Characteristics}

The age of the mothers gave birth by C/S range between 18-45 years old. 237(83.4\%), 20-35 years old, the rest were younger than 20 years old, 16 (5.6\%) and older than 35 years old, 31 (11\%), were 188(66\%) Urban and 96(36\%) Rural (Table 1).

\begin{tabular}{|c|c|c|c|}
\hline Variable & Categories & Frequency & Percent \\
\hline \multirow{3}{*}{ Age } & $16-19$ & 16 & $6 \%$ \\
\cline { 2 - 4 } & $20-35$ & 237 & $83 \%$ \\
\cline { 2 - 4 } & $>35$ & 31 & $11 \%$ \\
\hline \multirow{7}{*}{ Residence } & Urban & 188 & $66 \%$ \\
\cline { 2 - 4 } & Rural & 96 & $34 \%$ \\
\hline \multirow{7}{*}{ Occupation } & Housewife & 195 & $68.4 \%$ \\
\cline { 2 - 4 } & $\begin{array}{c}\text { Government } \\
\text { Worker }\end{array}$ & 41 & $14.4 \%$ \\
\cline { 2 - 4 } & Merchant & 34 & $11.9 \%$ \\
\cline { 2 - 4 } & Student & 14 & $4.9 \%$ \\
\hline
\end{tabular}

Table 1: Socio Demographic Characteristics of Mothers Who Delivered By Cs from July 2014-June 2017 at Jh under Study of Prevalence of Cs \& Maternal Complication (N=284) 


\section{Prevalence of CS}

During the period of study, there were 7284 deliveries at Jugol Hospital, of which 1620 were by C/S, prevalence of $22.2 \%$.

\section{Obstetrics Characteristics}

With regard to Obstetric characteristics, Out of the mothers delivered at hospital by c/s, 193(68\%) were multiparas and the rest were primiparas. 91 (32\%) of them had 2-3 anti natal care follow up, 245(86.2\%) had frequent (4) time anti natal care follow up while the rest $21(7.3 \%)$ had one anti natal care follow up. For majority of mothers (78.16\%), gestational age at labor was term \& majority (87.32\%) started labor spontaneously. Only $16.9 \%$ had previous one or more $\mathrm{C} / \mathrm{S}$ and $6.3 \%$ had comorbid medical conditions which were hypertension, asthma \&cardiac disease. $90.8 \%$ of babies are singleton and the remaining were twins (Table 2).

\begin{tabular}{|c|c|c|c|}
\hline Variables & Category & Frequency & Percent \\
\hline \multirow{3}{*}{$\begin{array}{c}\text { Number of ANC } \\
\text { visit }\end{array}$} & $<1$ & 18 & $6.34 \%$ \\
\hline & $2-3$ & 245 & $86.27 \%$ \\
\hline & $>4$ & 21 & $7.39 \%$ \\
\hline \multirow{2}{*}{ Parity } & Prim parity & 91 & $32 \%$ \\
\hline & Multiparty & 193 & $68 \%$ \\
\hline \multirow{3}{*}{ GA } & Preterm & 30 & $10.56 \%$ \\
\hline & Term & 222 & $78.17 \%$ \\
\hline & Post term & 32 & $11.27 \%$ \\
\hline \multirow{2}{*}{ Onset of labor } & Spontaneous & 248 & $87.32 \%$ \\
\hline & Induced & 36 & $12.68 \%$ \\
\hline \multirow{2}{*}{ Duration of labor } & Prolonged & 100 & $35.2 \%$ \\
\hline & Not prolonged & 184 & $64.8 \%$ \\
\hline \multirow{2}{*}{ Previous $\mathrm{c} / \mathrm{s}$} & Yes & 48 & $16.90 \%$ \\
\hline & No & 236 & $83.10 \%$ \\
\hline \multirow{3}{*}{ ROM } & After onset of labor & 254 & $89.4 \%$ \\
\hline & Before onset of labor & 14 & $14.9 \%$ \\
\hline & Prolonged PROM & 16 & $5.63 \%$ \\
\hline \multirow{3}{*}{$\begin{array}{l}\text { Number of } \\
\text { pregnancy }\end{array}$} & Singleton & 258 & $90.85 \%$ \\
\hline & Twin & 24 & $8.45 \%$ \\
\hline & Triplet \& above & 2 & $0.70 \%$ \\
\hline \multirow{2}{*}{ Type of c/s } & Emergency & 232 & $81.69 \%$ \\
\hline & Elective & 52 & $18.31 \%$ \\
\hline \multirow{2}{*}{$\begin{array}{l}\text { Comorbid } \\
\text { condition }\end{array}$} & Yes & 18 & $6.34 \%$ \\
\hline & No & 266 & $93.66 \%$ \\
\hline
\end{tabular}

Table 2: Obstetric History of Mother Who Deliver at Jh from July 2014-June 2017 by Cs under Study f Prevalence of Cs \& Maternal Complication (N=284)

\section{Mothers Post CS Complication Types and Rate}

$16.14 \%$ of mothers who gave birth by C/S during study period experienced at least one or more type of complication. From the total $46,51 \%$ of complication occurred, $20(7 \%)$ were puerperal sepsis and $10(3.52 \%)$ were postpartum hemorrhage and 1 (0.35\%) of mothers encompassing the rest percentage of complication. There were no maternal deaths (Table 3 ).

\begin{tabular}{|c|c|c|c|}
\hline Variables & Frequency & Percent & Cumulative frequency \\
\hline PPH & 10 & $3.52 \%$ & $31.25 \%$ \\
\hline Puerperal sepsis & 20 & $7 \%$ & $62.5 \%$ \\
\hline DVT & 2 & $0.70 \%$ & $6.25 \%$ \\
\hline Death & 0 & $0.00 \%$ & $0.00 \%$ \\
\hline
\end{tabular}

Table 3: Early Post C/S Complications Occurred on Mothers Who Deliver at

Jh by Cs under Study of Prevalence of Cs \& Maternal Complication ( $\mathrm{N}=284)$

The most frequently occurred puerperal sepsis was endomyometritis having $46.51 \%$ of infection followed by wound site infection $11.62 \%$, Urinary tract infection $6.9 \%$, deep vein thrombosis $4.65 \%$, uterine injury $4.65 \%$ and $2.32 \%$ have the remaining complications. Among mothers who developed PPH were two of them transfused at least 1 unit of blood and one of them undergone hysterectomy (Figure 1). 


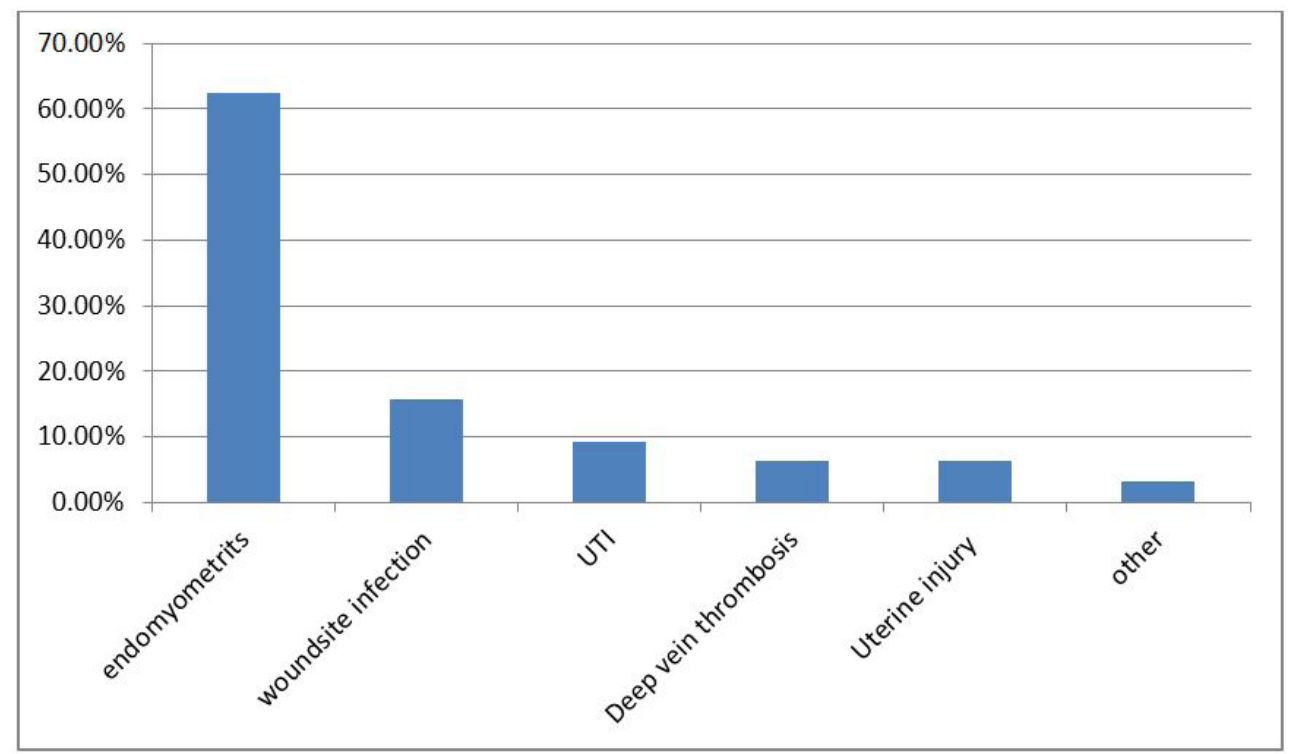

Figure 1: Types of Puerperal Sepsis Occurred among Mothers Who Deliver at Jh by Cs under Study of Prevalence of Cs \& Maternal Complication $(\mathrm{N}=284)$

Low ANC visit was associated with high incidence of infectious morbidity while most of PPH occurred in mothers who have optimal ANC. Both PPH \& infectious morbidity were high in mothers who undergone emergency C/S and who had prolonged labor. Most of post-partum hemorrhage and Puerperal sepsis occurred in term mothers who had no previous C/S\& comorbidity (Table 4).

\begin{tabular}{|c|c|c|c|c|c|c|c|c|c|}
\hline & & \multicolumn{7}{|c|}{ Type of Post CS complications rate } & \multirow{2}{*}{ Total } \\
\hline \multicolumn{2}{|c|}{ Obstetric variables } & PPH & Endometritis & $\begin{array}{l}\text { Wound site } \\
\text { infection }\end{array}$ & UTI & DVT & Uterine injury & Other & \\
\hline \multirow{3}{*}{ Age of mother } & $<20$ & 0 & 1 & 0 & 0 & 0 & 0 & 1 & 2 \\
\hline & $20-35$ & 9 & 16 & 5 & 3 & 2 & 2 & 0 & 37 \\
\hline & $36-45$ & 1 & 3 & 0 & 0 & 0 & 0 & 0 & 4 \\
\hline \multirow{3}{*}{ ANC visit } & $<1$ & 0 & 2 & 0 & 0 & 0 & 0 & 0 & 2 \\
\hline & 3-Feb & 10 & 17 & 5 & 3 & 2 & 2 & 0 & 39 \\
\hline & 4 & 0 & 1 & 0 & 0 & 0 & 0 & 1 & 2 \\
\hline \multirow{2}{*}{ Parity } & Primgravida & 4 & 10 & 1 & 2 & 0 & 1 & 0 & 18 \\
\hline & Multigravida & 6 & 10 & 4 & 1 & 2 & 1 & 1 & 25 \\
\hline \multirow{3}{*}{ GA } & Pre- term & 2 & 3 & 1 & 0 & 0 & 0 & 0 & 6 \\
\hline & Term & 7 & 12 & 3 & 2 & 1 & 2 & 1 & 28 \\
\hline & Post-term & 1 & 5 & 1 & 1 & 1 & 0 & 0 & 9 \\
\hline \multirow{2}{*}{ Type of C/S } & Emergency & 7 & 12 & 5 & 3 & 2 & 1 & 0 & 30 \\
\hline & Elective & 3 & 8 & 0 & 0 & 0 & 1 & 1 & 13 \\
\hline \multirow{2}{*}{ Onset of labor } & spontaneous & 6 & 19 & 5 & 3 & 1 & 1 & 1 & 36 \\
\hline & Induced & 4 & 1 & 0 & 0 & 1 & 1 & 0 & 7 \\
\hline \multirow{2}{*}{$\begin{array}{l}\text { Duration of } \\
\text { labor }\end{array}$} & Prolonged & 2 & 6 & 3 & 0 & 1 & 1 & 1 & 14 \\
\hline & Not prolonged & 8 & 14 & 2 & 3 & 1 & 1 & 0 & 29 \\
\hline \multirow{3}{*}{$\begin{array}{l}\text { Rupture of } \\
\text { membrane }\end{array}$} & After onset oflabour & 7 & 19 & 5 & 3 & 1 & 1 & 0 & 36 \\
\hline & Before onset of labour & 1 & 1 & 0 & 0 & 0 & 1 & 1 & 4 \\
\hline & PROM & 2 & 0 & 0 & 0 & 1 & 0 & 0 & 3 \\
\hline \multirow{2}{*}{ Previous C/S } & Yes & 5 & 2 & 0 & 0 & 1 & 1 & 0 & 9 \\
\hline & No & 5 & 18 & 5 & 3 & 1 & 1 & 1 & 34 \\
\hline \multirow{2}{*}{ Comorbidity } & Yes & 1 & 1 & 0 & 0 & 0 & 0 & 1 & 3 \\
\hline & No & 9 & 19 & 5 & 3 & 2 & 2 & 0 & 40 \\
\hline
\end{tabular}

Table 4: Association/ Relationship of Obstetric Characteristics of Mothers and Post Cs

Complications Rate at Jugal Hospital from July 2014-June 2017 (N=284) 


\section{Discussion}

The study shows that prevalence of Ceserean section in our study (22.2\%) was comparable to the finding at Jimma University hospital, Southwest Ethiopia in 2016 (22.2\%) and Addis Ababa (21.5\%) [16] while it is lower than research done at JUSH in 2014 which suggested a C/S rate of $28.1 \%$ [6]. Also the prevalence's of C/S in this study were lower than the prevalence s in United states $29.1 \%$, Brazil 36.4\% [5].This decrement from previous research might be due to increased number of residents experienced in doing instrumental vaginal deliveries and also increased mothers consent for vaginal deliveries after one previous $\mathrm{C} / \mathrm{S}$ scar. But still this value is greater than WHO recommended range.

In this study findings the prevalence's of Emergency C/S were $81.9 \%$, Elective CS were $18.31 \%$ when compared to the study result done at Shyam shah medical college in India 2016 emergency CS were $82.39 \%$ and $17.6 \%$ which is the same findings to this study results [17]. This could be due to socio demographic character of mothers like address, antennal care follow up and the presence of any comorbidity.

The absence of maternal mortality in this small sample at single hospital based research was explained by a very low mortality rate of the operation worldwide. Study that examined births between 2010 and 2011 in the Netherlands found that the risk of maternal death was 0.53 per 1000 cesarean deliveries and a review of nearly 1.5 million pregnancies in USA in 2008 [18], found maternal mortality rates of 2.2 per 100,000 cesarean deliveries [19]. Post C/S hemorrhage rate of $3.24 \%$ in this research is slightly greater than $1-2 \%$ post c/s transfusion range PPH in Europe [20]. This might be due high incidence of obstructed labor in the country as well as Jimma which poses difficult operation to easily control bleeding. Most of the mothers have also prolonged labor which leads to PPH due to high likelihood of post-partum uterine a tony after prolonged labor.

The routine use of prophylactic antibiotics at JUSH was also associated with clinically important reduction in postpartum febrile morbidity, wound infection and other serious infections. Good advice given for mothers to ambulate early after operation made the absence of venous thromboembolism in this research.

The result of this study shows out of the mothers delivered at hospital by c/s, 193(68\%) were multiparas and the rest were primiparas 91(32\%) of them had 2-3 anti natal care follow up, 245(86.2\%) had frequent (4) time anti natal care follow up while the rest 21(7.3\%) had one anti natal care follow up when compared to the study done at JSUH 2016 is relatively the same finding to our study results. were $64.4 \%$ multi Para and the rest were prim papa among these $87.7 \%$ of them $2-4$ ANC follow up, $6.4 \%$ had greater than 4 ANC follow up and the rest 5.8\% had no ANC follow up [15]. For majority of mothers (78.16\%), gestational age at labor was term \& majority (87.32\%) started labor spontaneously only $16.9 \%$ had previous one or more $\mathrm{C} / \mathrm{S}$ and $6.3 \%$ had comorbid medical condition which were hypertension, asthma \& cardiac disease. 258(90.8\%) of babies are single, 24(8.45\%) were twins and 2(0.70\%) were Triple. The result of this study shows were $81.69 \%$ emergency Ceserean section and $18.31 \%$ were elective Ceserean delivery when compared to study done at Shyam Shah Medical College in India in 2016 shows in group 1 (82.39\%) were emergency Ceserean section and $17.6 \%$ of elective Ceserean delivery, in group 2(71.6\%) were emergency and 28.4\% were elective Ceserean delivery [17].

The major complication occurred were 20(7\%) Endometritis, 10(3.52\%) PPH, 5(1.76\%) wound site infection, 3(1.05\%) urinary tract infection, 2(1.05\% ) deep vein thrombosis, 2(1.05\%) uterine injury, and 1(0.35\%) of mothers encompassing the rest percentage of complication. But the result of study conducted at Shyam Shah Medical College in India in 2016 shows maternal complication following CS Delivery were Atonic PPH occurred intra operatively 5.5\% of cases, extension of uterine incision occurred in 3.7\% of cases, Adhesion was present in $5.3 \%$ of cases, bladder injury occurred in $0.18 \%$ of cases, blood transfusion occurred in $1.07 \%$ of cases, and Anesthetic complication occurred in $1.18 \%$ of cases of CS delivery [17]. The most frequently occurred puerperal sepsis was endomyometritis having $62.5 \%$ of infection followed by wound site infection $15.62 \%$. Urinary tract infection, deep vein thrombosis and uterine injury have the remaining percentage. The result of our study showed that among those mothers developed $\mathrm{PPH}$ were two of them blood transfused and one of them undergone hysterectomy. When compared to study done at Jimma 2016 is significantly increases puerperal sepsis $10.38 \%$ and $\mathrm{PPH}$ were $3.24 \%$ [15]. This could be due to severity of maternal complications after Ceserean section.

Low ANC visit was associated with high incidence of infectious morbidity while most of PPH occurred in mothers who have optimal ANC due to the reason of not timely detect the problem and get advice and service from the health institution. Both PPH \& infectious morbidity were high in mothers who undergone emergency C/S and who had prolonged labor. Most of post-partum hemorrhage and puerperal sepsis occurred in term mothers who had no previous C/S \& comorbidity [15]. This could be due to socio demographic characteristic of mothers.

\section{Conclusion}

In summary, the overall prevalence of cesarean section in Jugol Hospital was $22.2 \%$. It is high compared to the WHO recommended for developing countries optimum upper limit of $15 \%$ prevalence. The prevalence of cesarean section in this study is not associated with higher rate of morbidity of mothers than developed country. The study result also showed that maternal complication occurred were 20(7\%) Endometritis, 10(3.52\%) PPH, 5(1.76\%) wound site infection, 3(1.05\%) urinary tract infection, 2(1.05\%) deep vein thrombosis, $2(1.05 \%)$ uterine injury, and $1(0.35 \%)$ of mothers encompassing the rest of complication. Low anti natal care follows up, emergency $\mathrm{C} / \mathrm{S}$ and prolonged labor is associated with high infections morbidity and $\mathrm{PPH}$. 


\section{Recommendation}

Different bodies like, administrative bodies health office, NGO and health workers should work on quality of services and ANC follow up so that pregnant mother get the care and decrease likelihood C/S and associated morbidity.

They should also give adequate post-partum care in order to early detect complication, prevent and treat them accordingly. Additionally, physician should encourage vaginal birth after previous $\mathrm{C} / \mathrm{S}$ scar by giving appropriate information for mothers and they shouldn't rush for $\mathrm{C} / \mathrm{S}$ unless clear indication come to picture in order to decrease the rise in $\mathrm{C} / \mathrm{S}$ rate.

Finally, we recommend that the regular $\mathrm{C} / \mathrm{S}$ case and outcome should documented clearly in easily accessible way so that health personnel evaluate the operation regularly in order to keep $\mathrm{C} / \mathrm{S}$ rate \& complication in acceptable range.

\section{Strength and Limitation of the study}

The strength of the study was the check list includes both physical and laboratory findings which aids to capture a more holistic, complete and complementary picture of the problem under study.

By design-since this study uses secondary record review the completeness of data was a major limitation.

\section{Acknowledgment}

We would like to extend appreciations to individuals who involved in data collection and Jugal hospital staffs who willingly gave us all the information we needed without any reservation.

\section{Authors' Contribution}

ML, MN and MT conceived the study, participated in the design, data analysis and interpretation of the result. ML involved in data acquisition, writing the draft manuscript as well as making all the changes as suggested by the coauthors. MN and MT critically reviewed the manuscript. All authors read and approved the manuscript.

\section{References}

1. Betrán AP, Merialdi M, Lauer JA, Bing-Shun W, Thomas J, et al. (2011) Rates of caesarean section: analysis of global, regional and national estimates. Paediatr Perinat Epidemiology 21: 98-113.

2. WHO (2013) UNFPA, World Bank. Trends in Maternal Mortality from 2010 to 2012. J Gynecol Obstet 2: 37-41.

3. Luz Gibones JB, Laves JA (2012) The global numbers and costs of additionally needed and unnecessary cesarean section performed per year, over use as a barrier to universal coverage. World health report 30: 1-4.

4. State-of-the-Science Conference Statement on cesarean delivery on maternal request: NIH Consents State Sic Statements (2013) 23: 1-29.

5. Menacker F, Declercq E, Macdorman MF (2011) Cesarean Delivery: Background, Trends, and Epidemiology. Semin Perinatol 30: 235-41.

6. Gebremedhin S (2014) Trend and socio-demographic differentials of Caesarean section rate in Addis Ababa, Ethiopia: analysis based on Ethiopia demographic and health surveys data. Reprod Health 11: 14.

7. Leone T, Padmadas SS, Mathews Z (2011) Community factor affecting rising caesarean section rates in developing countries: an analysis of six countries. Soc Sci Med. 67: 1236-46.

8. Shearer EL (2010) Cesarean section: medical benefits and costs. Soc Sci Med 37: 1223-31.

9. Thaddeus S, Maine D (2013) Too far to walk: maternal mortality in context. Soc Sci Med 38: 1091-110.

10. Todman D (2011) A history of cesarean section: From ancient to modern era. Aust N Z J Obstet Gynaecol 47: 357-61.

11. Sung JF, Daniels KI, Brodzinsky L, El-sayed YY, Caughey AB, et al. (2007) Cesarean delivery outcomes after prolonged second stage of labour. AM J Obstet Gynecol 197: 306.

12. Ethiopian Demographic Health Survey (EDHS) (2016) Ceserean section short term maternal complication. Ethioipian J pub H.

13. Ayanos Taye, Ahmed Yuya (2014) Department Of Nursing, Retrospective Analysis of Prevalence of C/S in JUSH. Ethioipian Jpub H 2014: 8-27.

14. Lurie S (2012) The changing motives of cesarean section: from ancient world to the twenty-first century. Arch Gynecol Obstet 271: 281-5.

15. Kebede D (2016) Department Of Nursing, Jimma University Medical College of Health, Prevalence and Outcome of C/S Jimma. Ethioipian J pub H $2016: 8$-13. 16. Gregory KD, Jackson SL, Korst LM, Fridman MY (2012) cesarean section versus vaginal delivery: whose risks Whose benefits? Am J Perinatology 29: 7-18.

17. College SSM (2016) cause of Ceserean section and its concern Rewa, Madhya Pradesh, Jawaharlal Nehru University, New Delhi - India Indian J publicH 110067. 18. Lumbiganon P, Laopaiboon M, Gulmezoglu AM, Souza JP, Taneepanichskul S, et al. (2010) Method of delivery and pregnancy outcomes in Asia: the WHO global survey on maternal and perinatal health 2007-08. Lancet 375: 490-9.

19. JP Souza, AM Gülmezoglu, P Lumbiganon, M Laopaiboon, G Carroli, et al. (2010) Caesarean section without medical indications is associated with an increased risk of adverse short-term maternal outcome: the 2004-2008 WHO Global Survey on Maternal and Perinatal Health. BMC Med 8: 71.

20. Victoria CG, Barros FC (2012) Beware: unnecessary caesarean sections may be hazardous. Lancet 367: 1796-7. 
Submit your next manuscript to Annex Publishers and
> benefit from:
$>$ Rasy online submission process
$>$ Online article availability soon after acceptance for Publication
$>$ Open access: articles available free online
Submit your manuscript at
http://www.annexpublishers.com/paper-submission.php 